\title{
Reflexiones sobre la Ingeniería en América Latina
}

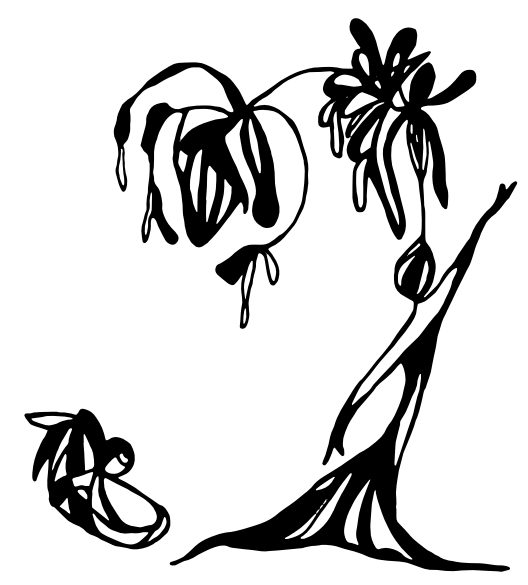

\section{Resumen}

La familia de América Latina tiene una cultura muy rica y grandes cantidades de recursos naturales, así como problemas y costumbres comunes. Hay enormes desafíos para la Ingeniería de América Latina como: la acreditación de las carreras de Ingeniería, la investigación en la enseñanza de la Ingeniería, la innovación, la movilidad de nuestros estudiantes, profesores y egresados, la homologación de planes curriculares, el reconocimiento de los grados y títulos y el ejercicio de la Ingeniería, entre otros. Por ello, se necesitan los mejores recursos de la Ingeniería de ayer y de hoy para explorar nuevas estrategias y para contribuir a la formación de los futuros ingenieros. Los países desarrollados, así como los países emergentes más exitosos, como México y Brasil, priorizan la ciencia, la tecnología y la innovación (CTI), hacen sostenidas inversiones en investigación y desarrollo (I\&D) para asegurar el crecimiento económico y el bienestar de su población; sin embargo, como región, los esfuerzos de inversión aún son muy bajos.

La Ingeniería es una de las profesiones más importantes para el desarrollo de un país, y formar profesionales en este campo es complejo, teniendo en cuenta que un gran porcentaje de egresados del nivel secundario prefiere seguir carreras de letras y no de Ingeniería. En la formación del ingeniero de hoy en América Latina, aún prima la educación especializada y restringida, ésta debe pasar a una educación holística interdisciplinaria, se necesitan los mejores recursos de la Ingeniería de ayer y de hoy para explorar nuevas estrategias y para contribuir a la formación de los futuros ingenieros.

en la que el alumno a través de "aprender haciendo aprenda a aprender" y que le sea natural interesarse por la cultura y ser parte de equipos de Ingeniería,en los que puedacomunicarse con eficacia verbal, escrita o gráfica interdisciplinariamente y en más de un idioma, aplicar la experiencia que enseña la historia y la cultura de aprender de los fracasos de la Ingeniería, así como poseer una sólida formación ética. Solo un compromiso auténtico y una colaboración sostenida entre todos los participantes involucrados en la educación de los ingenieros garantizarán un incremento substancial del número de ingenieros bien calificados y competitivos a nivel de América Latina.

\section{Los grandes problemas mundiales}

Es importante mencionar los grandes problemas globales que la Ingeniería enfrentará en el futuro, entre ellas mencionamos: el crecimiento de la población, que hoy pasa los siete mil millones de habitantes; la mayor demanda de energía, de agua, vivienda y alimentación; la vigente crisis financiera y económica; la acentuada corrupción en las actividades productivas y de servicio; pero el que tiene mayor relevancia es la crisis afectiva, producto de ello muchos jóvenes en el mundo se suicidan o son actores de matanzas; y la degradación ambiental sin límites, en particular en las zonas de explotación minera informal; entre otros. Este es el escenario actual y continuará en el futuro si no mejora la educación en todos los niveles. 
La población de los países en desarrollo se duplicará en los próximos veinte años y el $80 \%$ de esa población estará en la zona urbana. Hoy, un tercio de la población mundial vive en países con problemas de agua y de saneamiento básico, y para el año 2030 se espera que aumente a dos tercios. Frente a estos desafíos y escenarios, ¿cómo responderá la Ingeniería?

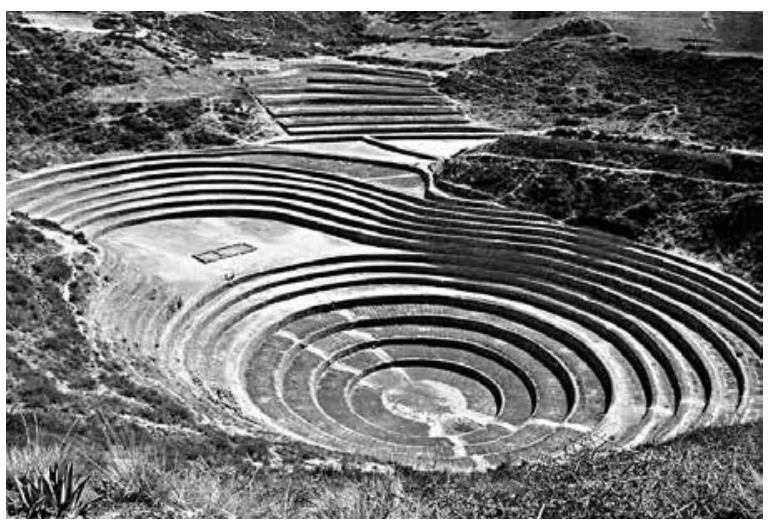

Las tendencias mundiales evidencian el rezago de América Latina en ciencia, tecnología e innovación. Como muestra de ello, con respecto a la población mundial, la producción de artículos científicos y tecnológicos representa solo el $2 \%$, la exportación de alta tecnología el 3\%, y el gasto e inversión en investigación y

El problema global más preocupante es el cambio climático, resultado del mal trato a la Tierra por actividades humanas, que han llevado al incremento del efecto invernadero, debido a la excesiva emisión de gases nitrosos, sulfurosos y, principalmente, del dióxido de carbono (CO2). Las investigaciones científicas han demostrado persistentemente que el incremento de la temperatura del planeta tendría consecuencias catastróficas, como el incremento de infernales sequías o diluvios provocados por torrenciales lluvias. En particular, Perú ya es uno de los países afectados por el deshielo de sus hermosas cordilleras. Por ello, es inaceptable el crecimiento económico ciego, a costa de destruir los ecosistemas y no pensar en las condiciones de vida para las generaciones futuras. En ese sentido, se hace necesario utilizar tecnologías limpias y formar ingenieros integrales con plena cultura de protección del ambiente.

\section{El estado actual}

El altísimo desarrollo de la ciencia y la tecnología en los siglos XX y XXI, y su impacto en todos los niveles de la vida demandan la modificación del paradigma de la persona culta, que ahora no solo debe relacionarse con el dominio de la literatura, de saber escribir y comunicarse, o de conocer las ciencias sociales, sino que debe extenderse al conocimiento de los principales resultados de la ciencia y la tecnología, tales como: energía, modificación genética, nuevos materiales, biotecnología, automatización, tecnologías de la información y comunicación(TIC) y nanotecnología, entre otros.

China e India se han incorporado al proceso de la globalización con una importante cantidad de ingenieros por ańo, y en América Latina se produce una fuerte demanda de ingenieros, pero los jóvenes no desean seguir estudios de Ingeniería.

desarrollo el 2\% (en el Perú no alcanza ni el 1\%).

Se aprecia también que los ingenieros tienen una mínima participación en el proceso político y se presenta la necesidad de apoyar más plenamente la sostenibilidad, dado que hay déficit en infraestructura física y aún no está controlada la pobreza. América Latina sigue siendo un continente exportador de materia prima sin valor agregado.

De este modo, América Latinaestáobligada a seguir un camino que le permita recuperar espacios frente a países más desarrollados, proteger su diversidad y el ambiente, darle valor a sus productos de escaso conocimiento, transformarse a una economía del conocimiento y convertirse en desarrollada y competitiva. Se requiereintroducir más capacidades empresariales e innovación en la formación del ingeniero.

\section{Los retos de la Ingeniería en América Latina}

Para América Latina, el primer reto es la mejora en la calidad de la educación en todos los niveles, con el fin de formar profesionales altamente competitivos para el mercado nacional y el resto del mundo. El papel de la Ingeniería será vital, tratando de buscar el desarrollo sostenible. En este contexto, los principales retos son:

- Globalización y competitividad.

- Cambio climático y medio ambiente.

- Tecnologías de la información.

- Modificación de los sistemas de aprendizaje.

La calidad de la formación profesional está dada por el desempeño de nuestros egresados en el mercado laboral. Aún existen las preferencias de las empresas y de la industria por ingenieros con un perfil específico y egresados de una determinada universidad. Hoy, como académicos en el marco de las reflexiones, nos preguntamos sobre nuestros egresados de Ingeniería: 
¿cuánto conocen de gerencia global y de innovación? ¿Qué trabajos de investigación han hecho?¿Cómo se enlazan con las exigencias de lo regional, nacional y mundial? ¿'Son emprendedores? ¿Tienen pensamiento sistémico? ¿Cómo los maestros universitarios estamos dimensionando adecuadamente el impacto de la globalización en nuestras instituciones y en la academia?

No se debe olvidar que estamos preparando ingenieros que van a ejercer su profesión en un escenario muy competitivo y agresivo. Un joven que empieza a estudiar hoy, en el año 2013, con la actual malla curricular o plan de estudios, :podrá ser competitivo en el año 2030? El agente más importante en la formación profesional son los docentes y como maestros universitarios debemos estar capacitados, integrados y compartir nuestras experiencias pedagógicas como latinoamericanos.

\section{La enseñanza de la Ingeniería}

La Ingeniería y la tecnología son subsistemas del sistema de educación y de un gran sistema social. Cada vez se interactúa más, también se ha discutido mucho sobre cuál debe ser el método o estilo que se debe privilegiar en la enseñanza de la Ingeniería. Existen instituciones educativas en las que el aprendizaje se fundamenta totalmente en el saber de los catedráticos o profesores. En particular, en mi generación el docente era el actor principal, el aprendizaje era a través de las clases magistrales con escasa opción a preguntas. También existen otros centros de estudio donde la enseñanza se hace con fundamento de la práctica y la experimentación, y hay casos en los que no se tieneque asistir, sino adquirir determinados conocimientos y demostrar que se tienen ciertas habilidades. Aún está en vigencia la enseñanza en la empresa, ella sirve de centro y laboratorio de aprendizaje y los conocimientos se complementan con la teoría que se da en las aulas de la academia. La comunidad o la zona rural es un gran laboratorio para la investigación y el aprendizaje en Ingeniería; el alumno y el profesor aplican los conocimientos y detectan las variables que influirán en el diseño.

En muy complejo establecer el método más óptimo sobre la enseñanza de la Ingeniería. En el siglo pasado, se privilegió las clases magistrales; hoy el profesor es un facilitador del aprendizaje. Se plantea que el alumno, a travésde aprender haciendo, aprenda a aprender, y que le sea natural interesarse por la cultura y forme parte de equipos de Ingeniería que le exijan comunicarse con eficacia verbal, escrita o gráfica, interdisciplinariamente, y, además, debe ser multilingüe. Hoy, se requiere ingenieros que lideren, que entiendan y manejen sistemas interdisciplinarios complejos, a través del poderoso método de la Ingeniería que es el diseño. Ellos solo pueden procederde una educación tan integral como integrada. El gran desafío para los académicos es formar ingenieros líderes, visionarios, emprendedores y comprometidos con su entorno social y con una noción clara del bien. La educación debe propender a la excelencia técnica con la capacidad de liderar, influir e integrar, y preparar al ingeniero para que pondere las distintas cuestiones sociales que conforman los planteamientos óptimos en torno a la planificación, el diseño y la construcción. Queda la necesidad de hacer sentir nuestra voz desde la academia, revisando nuestros planes curriculares, haciendo alianzas estratégicas que movilicen a profesores y estudiantes, que permitan generar una nueva conciencia de formación profesional acorde a los tiempos y a las necesidades de América Latina. Hoy, las instituciones universitarias tienen que ser las abanderadas para los cambios en el campo de la enseñanza de la Ingeniería.

Mirar hacia delante, hacia lo desconocido, presenta un considerable riesgo. Es posible que algunas realidades del futuro no se adviertan y que algunos aspectos de la visión terminen revelándose en un espejismo. La visión de la Ingeniería en América Latina, a través de la enseñanza, debe formar un ingeniero líder y multilingüe, que maneje sostenidamente nuestros recursos naturales, consolide la identidad de América Latina, se adapte al cambio, domine las herramientas informáticas con destreza, tenga una cultura de aprendizaje continuo,maneje los riesgos y conozca de política pública. Solo un compromiso auténtico y una colaboración sostenida entre todos los participantes involucrados en la educación de los ingenieros garantizarán un incremento substancial del número de ingenieros bien calificados y competitivos a nivel de América Latina.

\section{Conclusiones}

- Hay una necesidad urgente de revisar los planes curriculares en la formación del Ingeniero en América Latina.

- Es necesario fortalecer la movilidad estudiantil y docente.

- La capacitación en herramientas pedagógicas para los docentes en Ingeniería es de vital importancia.

- La integración de la Ingeniería en América Latina cobra cada vez mayor fuerza en los procesos de enseñanza-aprendizaje.

- En los planes curriculares se deben incluir asignaturas sobre innovación, liderazgo y políticas públicas. 